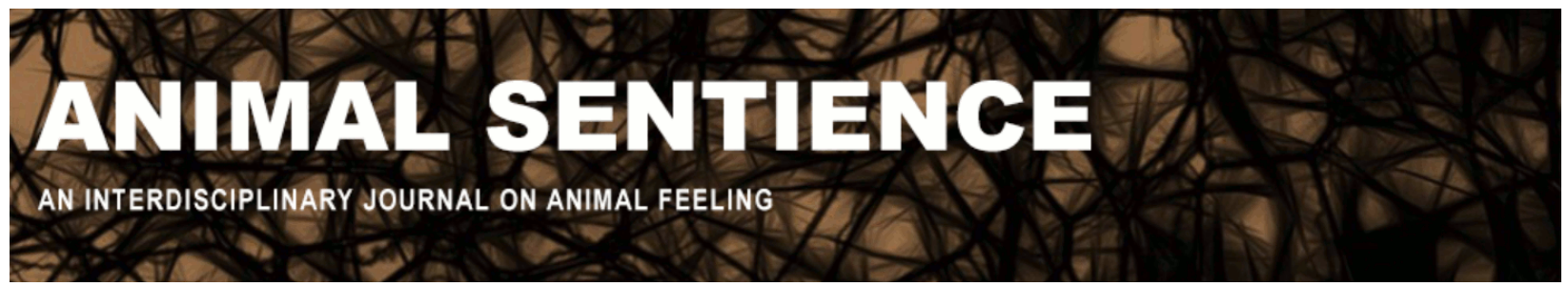

Hood, S. Brian and Giddens, Sophia (2019) Phenotypic similarity and moral consideration. Animal Sentience 23(35)

DOI: $10.51291 / 2377-7478.1415$

Date of submission: 2019-02-11

Date of acceptance: 2019-02-20

(c)

This article has appeared in the journal Animal

Sentience, a peer-reviewed journal on animal

cognition and feeling. It has been made open access,

free for all, by WellBeing International and deposited

in the WBI Studies Repository. For more information,

please contact

wbisr-info@wellbeingintl.org.

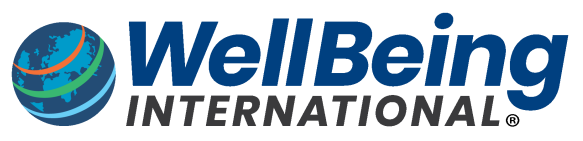

SOLUTIONS FOR PEOPLE, ANIMALS AND ENVIRONMENT 


\title{
Phenotypic similarity and moral consideration
}

Commentary on Chapman \& Huffman on Human Difference

\author{
S. Brian Hood \& Sophia Giddens \\ Department of Philosophy, University of West Florida, Pensacola, Florida
}

\begin{abstract}
Identifying specific traits to justify according differential moral status to humans and non-human animals may be more challenging than Chapman \& Huffman suggest. The reasons for this also go against their recommendation that we ought to attend to how humans and nonhumans are similar. The problem lies in identifying the moral relevance of biological characteristics. There are, however, other reasons for treating non-human animals as worthy of moral consideration, such as the Precautionary Principle.
\end{abstract}

\begin{abstract}
S. Brian Hood is Associate Professor and Chair of Philosophy at the University of West Florida. His research interests include animal ethics, the philosophy of science, and the philosophy of psychiatry. He has written on the concept of validity in psychometrics, the practical relevance of debates in the philosophy of science for clinical psychologists, and other topics. Website
\end{abstract}

Sophia Giddens is a senior at the University of West Florida. Her interests include philosophy of science, epistemology, and the brain sciences. Website
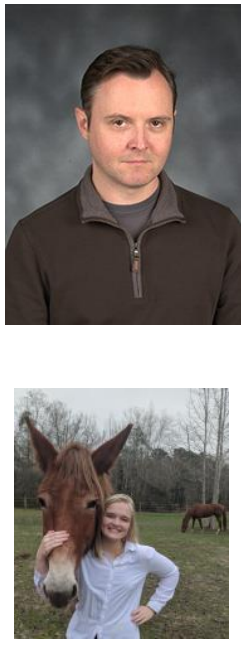

Chapman \& Huffman (2018) (C \& H) argue that attempts to specify human phenotypic traits to justify ascribing elevated moral status to humans have failed. From personhood to tool use, including the use of plants for their medicinal properties, each trait alleged to be the characteristic that justifies viewing humans as "superior" has proved to be shared by other animals. Conversely, Singer (2009) and others argue that for any putative unique trait (e.g., ability to acquire and use natural languages, levels of cognitive ability, and capacity for empathy), there will be some humans who lack it yet are accorded moral consideration. Thus the problem seems to be two-sided: to identify human uniqueness that would justify elevated moral status, the relevant traits identified would need to satisfy three criteria:

1. only modern humans possess the traits at or above some specified level

2. all modern humans possess them

3. the traits are conceptually linked to differential moral status warranting elevated moral consideration 
As C \& $\mathrm{H}$ point out, efforts to specify traits meeting the first and second criteria have been unsuccessful. Attempts to satisfy the third criterion face serious challenges as well. There is no reason a group judged "superior" with respect to some trait should be entitled to more rights or freedom from harm. Allen (2006) expresses pessimism about specifying such traits, noting a gap between "those properties of animals that are part of the scientific consensus, and those to which ethicists typically appeal in their arguments."

$\mathrm{C} \& \mathrm{H}$ suggest that rather than focusing on the differences between humans and nonhumans, we should focus on their similarities. Doing so would inform human dietary choices and teach us about non-human animals. The problem is that candidate characteristics thus far have either been arbitrary, not unique to humans, not shared by all humans, or not relevant to ascriptions of differential moral status. Human/non-human similarities run comparable risks, including arbitrariness and anthropocentric bias.

C \& $\mathrm{H}$ are right that differences in themselves are value-free, but according moral significance based on similarity in some trait is not. An alternative approach would be to focus on the capacity of non-human animals to suffer. Operationalizing "suffering" and the phenomenology of pain (apart from its biological underpinnings such as nociception or anterior cingulate cortical activity) scientifically and ethically is a challenge. Until this challenge is met, or we gain a better understanding of animal cognition, the Precautionary Principle (Birch 2017) would recommend treating non-humans with dignity and moral consideration. The cost of incorrectly ascribing moral status seems lower than the cost of incorrectly denying it.

\section{References}

Allen, C. (2006) Ethics and the science of animal minds. Theoretical Medicine and Bioethics, 27, 375-394.

Birch, J. (2017) Animal sentience and the precautionary principle. Animal Sentience 16(1). Singer, P. (2009) Animal liberation. New York, NY: HarperCollins Publishers. 